\title{
Oil-well climate catastrophe?
}

\section{London}

ThE British Meteorological Office is assessing the climatological impact of a war in the Persian Gulf, after delegates to a hastily convened conference in London last week suggested that Iraqi sabotage of Kuwait's oil wells could cause an environmental catastrophe.

The fears expressed last week centred around the cloud of soot that would result if Kuwait's oil wells were set alight by Iraqi forces, and the possibility that this could block out sunlight, with effects similar to those of the 'nuclear winter' much discussed some years ago as a consequence of an all-out nuclear war.

John Houghton, director of the Meteorological Office, hopes to have a preliminary climatological analysis later this week, before the 15 January deadline set by the UN Security Council for Iraqi forces to leave Kuwait. "We don't think there's a major climate problem", he says, but adds that "it is something we have to look at", given the publicity attracted by the London conference.

Before the Iraqi invasion, Kuwait produced more than two million barrels of oil a day from 365 active wells, of which 343 required no artificial pumping and so could flow freely (probably at a slightly higher rate than when controlled). The fear is that the wells would continue to burn if they were ignited. Given that there are only a handful of specialist oil-well fire-fighting teams around the world, it could take from six months to a year to extinguish all the fires if most Kuwaiti wells were sabotaged.

At the London meeting, John Cox, a consultant chemical engineer to the oil industry who is also a vice-president of the British organization Campaign for Nuclear Disarmament, said 3 million barrels of oil a day could burn if all the Kuwaiti wells were sabotaged. Abdullah Toukan, science adviser to King Hussein of Jordan, also attended the London meeting and says that as much as 10 million barrels of oil a day could burn if a proportion of Kuwait's many out-ofcommission oil wells were also set alight. But Iraq may be deterred from such widespread sabotage by the fact that the worst environmental effects would be felt in the Gulf region, including Iraq.

The Meteorological Office study has been requested by a number of government departments. Keith Browning, director of research, says that there is too little time to run any detailed computer simulations, and is aiming at a short "common-sense assessment". Browning's calculations are based on the burning of 2 million barrels of oil a day if most wells are sabotaged, but his team will also produce analyses based on partial sabotage of the
Kuwaiti oil fields and for a worst-case situation.

Taking Toukan's figure of 10 million barrels a day, Paul Crutzen, from the Max Planck Institute for Chemistry in Mainz, has produced some rough calculations which predict a cloud of soot covering half of the Northern Hemisphere within 100 days. Crutzen stresses that he cannot vouch for the accuracy of the Jordanian figure, but estimates that temperatures beneath such a cloud could be reduced by $5-10^{\circ} \mathrm{C}$ in the short term.

But this tentative forecast requires that soot particles should reach the stratosphere if they are to have anything other than a regional effect. Some climate scientists doubt whether the blazing oil wells could create sufficiently strong convection currents to deposit soot into the upper atmosphere.

The problem for the Meteorological Office team is that very little work has been done on the circulation patterns set up by large fires. Martin Miller, from the European Centre for Medium-Range Weather Forecasting in Berkshire, who works on convection currents in natural weather systems, says that there has been some work on forest fires, but "it's a very imprecise science". David Shillito, from the consultant chemical engineers Cremer and Warner, adds that a detailed climatological assessment of the sabotage would require data on the likely yield of carbon from the fires, and on the size distribution of soot particles - parameters that may vary from well to well.

Last week's conference was organized by Penny Kemp, a writer on environmental issues, and was attended by a range of interested parties, including environmental engineers, representatives of the oil industry and peace campaigners. Kemp says that a similar meeting will be held in the United States this week. The warnings of global disaster have been featured prominently by the British media, but were dismissed as "misleading" by the Secretary of State for Energy in the British government, John Wakeham.

The possibility of an environmental catastrophe in the Gulf was first raised by King Hussein in his speech to the World Climate Conference in Geneva last November, when he said global warming could be accelerated by the burning of Kuwait's oil reserves. But many climate scientists say that the sabotage of Kuwait's oil wells, against the background of worldwide fossil fuel burning, would have only a small warming effect. Tom Wigley, from the University of East Anglia, says he would expect sabotage of Kuwait's oil wells to produce only a small "blip" in the global atmospheric carbon dioxide concentration.

Peter Aldhous
First winner in detector race

\section{San Francisco}

The Superconducting Super Collider (SSC) Laboratory last week announced which two of three contending groups may build $\$ 500$-million particle detectors for the accelerator. The results: one clear winner, one group out of the running and one asked to try again after revamping its collaboration.

The Solenoidal Detector Collaboration (SDC), led by George Trilling of the University of California's Lawrence Berkeley Laboratory, was given the go-ahead to develop a formal design proposal, to no great surprise in the high-energy physics community. The SDC combines a proven technological approach with respected leadership, and was the only proposal with the broad general-purpose capability for tracking particles that the project requires of one of the two large detectors.

The youngest and smallest collaboration to propose a detector was EMPACT/ TEXAS, headed by Michael Marx of the State University of New York at Stony Brook. This scheme has been turned down by the SSC's Program Advisory Committee (PAC), which concluded that it is impressive but risky.

Still undecided is the fate of the proposed Lone Star detector, widely known as $\mathrm{L}^{*}$, piloted by Samuel Ting of the Massachusetts Institute of Technology, who is at present the spokesman for the L3 detector at the successful Large Electron-Positron collider (LEP) at CERN in Geneva.

$L^{*}$ was denied approval at this stage, but an amended proposal would be considered. The committee has made two particular suggestions. One is that, in what is essentially a multi-national collaboration, the proportion of US participants should be increased. This would reduce the financial vulnerability of the United States should one or more of the foreign participants back out.

SSC also asks that the top-level management of the project should be strengthened and expressed anxiety about the cost estimates for $L^{*}$, suggesting that the laboratory should independently review the figures to tell whether the costs are feasible.

One possibility now is that physicists from EMPACT/TEXAS will join forces with $L^{*}$ and Ting says the two groups are discussing options such as this.

With or without the former competitors as team-members, Ting says he expects to report back to SSC in February for reconsideration. Formal proposals from Trilling's SDC and from $L^{*}$, if approved, are due in April 1992. Planners hope the SSC itself will be completed in 1999 at a cost of about $\$ 8,250$ million.

Elizabeth Schaefer 